\title{
Effect of XPD and TP53 Gene Polymorphisms on the Risk of Platinum-Based Chemotherapy Induced Toxicity in Bangladeshi Lung Cancer Patients
}

\author{
Tahsin Nairuz ${ }^{1}$, Most Umme Bushra², Yearul Kabir ${ }^{3 *}$
}

\begin{abstract}
Background: Platinum-based drugs, including cisplatin and carboplatin, are the most active and extensively used agents for treating lung cancer. Genetic polymorphisms of DNA repair gene XPD and tumor suppressor gene TP53 are connected with alterations in enzyme activity. They may help explain interindividual differences in toxicity outcomes after platinum-based chemotherapy for lung cancer. Therefore, this study aimed to investigate XPD Lys751Gln and TP53 Arg72Pro polymorphisms on the risk of platinum-based chemotherapy-induced toxicity in lung cancer patients in the Bangladeshi population. Patients and Methods: Study subjects comprised of 180 platinum-based chemotherapy treated histologically confirmed lung cancer patients. Genetic polymorphisms of XPD were ascertained by Polymerase Chain Reaction-based Restriction Fragment Length Polymorphism (PCR-RFLP), while TP53 genotypes were analyzed using the multiplex PCR-based method. Toxicity was assessed based on the Common Terminology Criteria for Adverse Events (CTCAE v5.0). Results:From the results, there was no significant association observed between grade 1-2 or grade 3-4 platinum-based chemotherapy induced toxicities like anemia and XPD codon 751 (Lys/Gln: OR=1.40, 95\% $\mathrm{CI}=0.75-2.64, \mathrm{p}>0.05 ; \mathrm{Gln} / \mathrm{Gln}: \mathrm{OR}=1.07,95 \% \mathrm{CI}=0.45-2.52, \mathrm{p}>0.05$ and $\mathrm{Lys} / \mathrm{Gln}+\mathrm{Gln} / \mathrm{Gln}: \mathrm{OR}=1.31,95 \% \mathrm{CI}=0.73-$ $2.38, \mathrm{p}>0.05$ ) or TP53 codon 72 genetic polymorphisms (Arg/Pro: $\mathrm{OR}=0.64,95 \% \mathrm{CI}=0.34-1.17, \mathrm{p}>0.05$; Pro/Pro: $\mathrm{OR}=0.46,95 \% \mathrm{CI}=0.15-1.42, \mathrm{p}>0.05$ and $\mathrm{Arg} /$ Pro+Pro/Pro: $\mathrm{OR}=0.62,95 \% \mathrm{CI}=0.34-1.15, \mathrm{p}>0.05)$. Similar results were found between neutropenia, leukopenia, thrombocytopenia and gastrointestinal toxicities and XPD Lys751Gln or TP53 Arg72Pro genetic polymorphisms. Conclusion: These findings indicated that no significant association was found between either XPD codon 751 or TP53 codon 72 genetic polymorphisms and platinum-based chemotherapyrelated toxicities in Bangladeshi lung cancer patients.
\end{abstract}

Keywords: Lung cancer- XPD- TP53- genetic polymorphism- platinum-based chemotherapy

Asian Pac J Cancer Prev, 22 (12), 3809-3815

\section{Introduction}

Lung cancer has become one of the cancers with high morbidity and mortality, and its global incidence is rising year by year. A relatively high incidence of lung cancer is observed in the Bangladeshi population, where it is the most prevalent cancer in males considering an incidence rate of $14.2 \%$ (Sung et al., 2021). In Bangladesh, the estimated lung cancer patients were found to be 196,000 , and among them, $85 \%$ are aged 30 years or above (Hussain and Sullivan, 2013). Following the data published by the World Health Organization in 2017, lung cancer deaths in Bangladesh rise to 12,075 or $1.53 \%$ of total deaths (WHO, 2017). According to the GLOBOCON 2020 report, there were 12,999 (8.3\%) new lung cancer cases in Bangladesh in 2020, considering both sexes and all ages (Sung et al., 2021).
Lung cancer treatment relies on cancer's specific cell type, the extent of spread, and the person's performance status. Platinum-based chemotherapy is widely accepted as a first-line treatment for patients with locally advanced non-small-cell lung cancer (NSCLC), where radiotherapy cannot be used for treatment and in those with non-small-cell lung cancer at the metastatic stage with good performance status. The platinum compounds mostly applied in NSCLC are cisplatin and carboplatin. Numerous randomized clinical trials along with metaanalyses have proved the supremacy of platinum-based over non-platinum-based therapy (Pujol et al., 2006; D'Addario et al., 2005). Some agents, paclitaxel, docetaxel, gemcitabine, and vinorelbine, have been included in platinum-based therapy doublets and have been confirmed to be equally important efficient. Unfortunately, after treatment, survival rates for patients are still low at

${ }^{1}$ Department of Biochemistry and Molecular Biology, Noakhali Science and Technology University, Bangladesh. ${ }^{2}$ Department of Pharmacy, Manarat International University, Bangladesh. ${ }^{3}$ Department of Biochemistry and Molecular Biology, University of Dhaka.Bangladesh. *For Correspondence: ykabir@yahoo.com 
only 29\% (NSCLC Meta-Analyses Collaborative Group, 2008). However, the prime obstacle to effective treatment with cisplatin, carboplatin, and other platinum agents is the occurrence of chemoresistance and various associated toxicities that restrict these agents from gaining their full potential (Hildebrandt et al., 2009).

Platinum-based therapies are related to significant increases in several toxicities and nausea and vomiting. Platinum-induced anemia can be occurred due to various factors, such as early reduction in hemoglobin level after treatment, old age, cumulative platinum dose, inability to respond to chemotherapy, and following administration accumulation of the high amount of residual platinum in the bloodstream (Clarke and Pallister, 2005; Pivot et al., 2000). Cisplatin-associated toxicities vary from mild to severe, with nephrotoxicity and peripheral neurotoxicity considered the most severe. For carboplatin, hematological toxicity is dose-limiting, with thrombocytopenia being a more prominent problem than leucopenia. Even though carboplatin is non-toxic to the kidney, renal function considerably alters the carboplatin-induced thrombocytopenia severity (Glezerman and Jaimes, 2016).

Several polymorphisms have been reported as crucial for the function and metabolism of platinum drugs; most of them frequently occur in DNA repair genes. Genetic polymorphisms in these pathways are associated with multiple toxicity effects and are considered predictive tools for the pretreatment assessment of platinum-containing chemotherapy toxicities. Xeroderma pigmentosum complementary group $\mathrm{D}$ (XPD/ERCC2) has an ATP-dependent DNA helicase activity involved in NER (Nucleotide Excision Repair) as well as in basal transcription being a part of the transcription factor IIH. Polymorphisms in XPD alter DNA repair and are associated with chemotherapy resistance, survival, and cancer appearance (Benhamou and Sarasin, 2002; Giovannetti et al., 2011). XPD Lys751Gln polymorphism can modify the total DNA repair efficacy and participate in removing platinum-DNA adducts, which can underpin the antitumor potential of platinum drugs if persist (Jung and Lippard, 2007).

The $\mathrm{p} 53$ protein, in comparison to the DNA repair proteins, does not appear to influence cisplatin transformation or metabolism directly. Nevertheless, it plays a significant task in mediating the cellular responses to DNA damage (Jung and Lippard, 2007). The Arg72Pro polymorphism is being located in the proline-rich region of p53, where the replacement of Arg with Pro may directly modulate the presumed SH3-binding domain structure. In addition, the Arg72 protein is more effective in apoptosis function, while the Pro72 form initiates more G1 arrest and is much superior at mediating p53-dependent DNA restore (Bojesen and Nordestgaard, 2008).

Nevertheless, the application of genotypic analysis of XPD and TP53 genes as a predictor of clinical outcome to platinum-based treatments remains controversial, and additional studies are needed. Therefore, the present study was carried out to evaluate the possible correlations of XPD Lys751Gln and TP53 Arg72Pro polymorphisms with the toxicity of platinum-based chemotherapy in Bangladeshi patients with lung cancer.

\section{Materials and Methods}

\section{Patients Selection Criteria}

The study was carried out following the provisions of the recent version of the Helsinki Declaration (WMA, 2013) and after approval by the Ethical Review Committees of the Department of Biochemistry and Molecular Biology, University of Dhaka. A total of 180 lung cancer patients with histologically diagnosed lung cancer as per the International Association of Lung Cancer (Travis, 2011) reported to Ahsania Mission Cancer and General Hospital, Dhaka Medical College Hospital, and Bangabandhu Sheikh Mujib Medical University formed the study group. Before enrollment, all the patients were explained about the investigational nature of this protocol, and informed consent was received from each patient. Patients with a previous history or record of other severe diseases such as kidney disease, cardiovascular disease, and other metastasized cancer were excluded from the study. Patients' details were collected using a structured questionnaire regarding age, gender, chemotherapyrelated toxicities, and family history of chronic diseases.

\section{Toxicity Evaluation Criteria}

Toxicities of platinum-based chemotherapy like anemia, neutropenia, leukopenia, thrombocytopenia, and gastrointestinal toxicity in lung cancer patients were evaluated according to the National Cancer Institute for Common Terminology Criteria for Adverse Events version 5.0 (CTCAE v5.0) (2017).

\section{Sample Collection and DNA Extraction}

About three milliliters $(3.0 \mathrm{~mL})$ of venous blood samples were obtained from patients in sterile tubes (EDTA-Na2-containing) for genotyping study and stored at $-20^{\circ} \mathrm{C}$ until DNA extraction. Genomic DNA was extracted using the organic extraction procedure described by Bailes et al., (2007).

\section{Genotyping Assay}

A genotyping assay of XPD was performed by PCR-Restriction Fragment Length Polymorphism (RFLP) method. On the other hand, TP53 genotype was assessed by allele-specific multiplex PCR method where PCR assay performed individually for identifying the presence of either Arg or Pro p53 polymorphic allele. The primer sequences and PCR conditions were derived from the previously published papers (Mitra et al., 2009; Papadakis et al., 2002). For RFLP, the PCR product (413 bp) of XPD Lys 751Gln SNP was digested with the restriction enzyme PstI $\left(37^{\circ} \mathrm{C}\right.$ for 16 hours in a water bath). Enzyme digestion product was electrophoresed through a $3 \%$ agarose gel following ethidium bromide staining to visualize the targeted XPD fragments of $413 \mathrm{bp}, 322 \mathrm{bp}$, and $91 \mathrm{bp}$. For TP53, the $\beta$-globin gene serves as an internal control to avoid false-negative readings. The co-amplified PCR products of TP53 were analyzed on a $2 \%$ agarose gel following staining with ethidium bromide. The Arg allele and Pro allele presence were confirmed by $199 \mathrm{bp}$ and 177 bp PCR amplified products. 


\section{Statistical Analysis}

According to toxicity grades, the Fisher's exact tests were performed through GraphPad Prism, version-8, to assess the association between genotype and platinumbased chemotherapy-induced toxicity. The relative association between them was determined by calculating the odds ratio (OR) with $95 \%$ confidence intervals (CIs) and level of significance (p). A p $<0.05$ was regarded as the level of significance.

\section{Results}

\section{Patient characteristics}

In this study, a total of 180 lung cancer patients were recruited and analyzed. The included patients were aged between 40 and 85 years with a mean age of $55.83 \pm 0.66$ years. Most lung cancer patients were above 50 years $(\mathrm{n}=137,76.11 \%)$ and administered with platinum-based chemotherapeutic agents. Among 180 patients with lung carcinoma, 109 patients were males, and 71 patients were females. Moreover, 128 lung cancer patients (71.11\%) were smokers, whereas only 52 patients $(28.89 \%)$ were nonsmokers. Among the cases, stage IIIB represented the highest frequency at $65 \%$ (117 patients) compared with stage IIIA at 35\% (63 patients). The details of different combination of chemotherapy received by lung cancer patients were recorded as carboplatin + paclitaxel, $31.67 \%$ (57 patients); carboplatin + gemcitabine, $23.33 \%$ (42 patients); cisplatin + etoposide, 18.89 (34 patients); cisplatin + paclitaxel, 7.22\% (13 patients); cisplatin + docetaxel, 6.67 (12 patients); carboplatin + etoposide, $5 \%$ (9 patients); carboplatin + docetaxel, 3.89\% (7 patients); and carboplatin + doxorubicin, $3.33 \%$ (6 patients) (Table 1).

\section{Toxicity to chemotherapy}

Toxicity outcomes presented in Table 1 were recorded in platinum-based chemotherapy-treated lung cancer patients. These toxicities were grouped into (a) under grade 1-2 toxicity (b) under grade 3-4 toxicity shown in two columns. Here, grade refers to the severity of different platinum-based chemotherapy-induced toxicities. The most frequent toxicities observed included anemia, neutropenia, leukopenia, thrombocytopenia, and GI toxicity. Both 1-2 and 3-4 grades anemia were observed in $90(50 \%)$ patients. On the other hand, grade 1-2 neutropenia was observed in 97 (53.89\%) patients, whereas grade 3-4 neutropenia was observed in 83 (46.11\%) patients. Moreover, 115 (63\%) patients were found with grade 1-2 leukopenia, while 65 (36.11\%) patients were identified with grade 3-4 leukopenia. Among the hematological toxicities, the highest percentage $(81.67 \%)$ of patients was found with grade $1-2$ thrombocytopenia, whereas the number of patients with grade 3-4 thrombocytopenia was minimal (33 patients). The only non-hematological toxicity included in this study was GI toxicity, where 1-2 grade GI toxicity occurred in $141(78.33 \%)$ patients, and 3-4 grade GI toxicity occurred in $39(21.67 \%)$ patients. However, during the study, no serious adverse events were reported.
$X P D$ Lys 751 Gln genotype analysis and effects on platinum-based chemotherapy-induced toxicities

Among 180 lung cancer patients, the frequencies of XPD genotypes, homozygous wild type (Lys/Lys), heterozygous mutant variant (Lys/Gln), homozygous mutant variant $(\mathrm{Gln} / \mathrm{Gln})$, and combined mutant variant (Lys/Gln+Gln/Gln) were $44.44 \%$ (80 patients), $41.67 \%$ (75 patients), $13.89 \%$ (25 patients) and 55.56\% (100 patients) respectively.

Table 1. Basic Characteristics, Treatment, and Toxicity of the Study Patients

\begin{tabular}{|c|c|}
\hline Characteristics & $\begin{array}{c}\text { Cases }(\mathrm{n}=180) \\
\mathrm{n}(\%)\end{array}$ \\
\hline Age (Year)a & $55.83 \pm 0.66$ \\
\hline \multicolumn{2}{|l|}{ Age distribution } \\
\hline$<50$ years & $43(23.88) b$ \\
\hline$>50$ years & $137(76.11)$ \\
\hline \multicolumn{2}{|l|}{ Gender } \\
\hline Male & $109(60.56)$ \\
\hline Female & $71(39.44)$ \\
\hline \multicolumn{2}{|l|}{ Smoking status } \\
\hline Non smokers & $52(28.89)$ \\
\hline Smokers & $128(71.11)$ \\
\hline \multicolumn{2}{|l|}{ Staging } \\
\hline Stage IIIA & $63(35.00)$ \\
\hline Stage IIIB & $117(65.00)$ \\
\hline \multicolumn{2}{|l|}{ Chemotherapy Regimens } \\
\hline Carboplatin + Paclitaxel & $57(31.67)$ \\
\hline Carboplatin + Gemcitabine & $42(23.33)$ \\
\hline Cisplatin + Etoposide & 34 (18.89) \\
\hline Cisplatin + Pacitaxel & $13(7.22)$ \\
\hline Cisplatin + Docetaxel & $12(6.67)$ \\
\hline Carboplatin + Etoposide & $9(5.00)$ \\
\hline Carboplatin + Docetaxel & $7(3.89)$ \\
\hline Carboplatin + Doxorubicin & $6(3.33)$ \\
\hline \multicolumn{2}{|l|}{ Toxicity } \\
\hline \multicolumn{2}{|l|}{ Anemia } \\
\hline Grade 1-2 & $90(50.00)$ \\
\hline Grade 3-4 & $90(50.00)$ \\
\hline \multicolumn{2}{|l|}{ Neutropenia } \\
\hline Grade 1-2 & $97(53.89)$ \\
\hline Grade 3-4 & $83(46.11)$ \\
\hline \multicolumn{2}{|l|}{ Leukopenia } \\
\hline Grade 1-2 & $115(63.89)$ \\
\hline Grade 3-4 & $65(36.11)$ \\
\hline \multicolumn{2}{|l|}{ Thrombocytopenia } \\
\hline Grade 1-2 & $147(81.67)$ \\
\hline Grade 3-4 & $33(18.33)$ \\
\hline \multicolumn{2}{|l|}{ GI toxicity } \\
\hline Grade $1-2$ & $141(78.33)$ \\
\hline Grade 3-4 & $39(21.67)$ \\
\hline
\end{tabular}

${ }^{a}$ Mean \pm SEM; ${ }^{b}$ Numbers in parentheses show percentages.

Asian Pacific Journal of Cancer Prevention, Vol $22 \mathbf{3 8 1 1}$ 
Table 2. XPD (Codon 751) Genotypes Effect on Platinum-Based Chemotherapy-Induced Toxicities According to Toxicity Grades

\begin{tabular}{|c|c|c|c|c|c|}
\hline Toxicities & Genotypes & Grade $1-2$ & Grade 3-4 & OR $(95 \% \mathrm{CI})$ & $\mathrm{p}$ value \\
\hline \multirow[t]{4}{*}{ Anemia } & Lys/Lys & 43 & 37 & 1.0 (Ref.) & - \\
\hline & Lys/Gln & 34 & 41 & $1.40(0.75-2.64)$ & 0.34 \\
\hline & $\mathrm{Gln} / \mathrm{Gln}$ & 13 & 12 & $1.07(0.45-2.52)$ & 0.99 \\
\hline & Lys/Gln+Gln/Gln & 47 & 53 & $1.31(0.73-2.38)$ & 0.45 \\
\hline \multirow[t]{4}{*}{ Neutropenia } & Lys/Lys & 46 & 34 & 1.0 (Ref.) & - \\
\hline & Lys/Gln & 38 & 37 & $1.32(0.71-2.49)$ & 0.42 \\
\hline & $\mathrm{Gln} / \mathrm{G} \ln$ & 13 & 12 & $1.25(0.52-2.94)$ & 0.65 \\
\hline & Lys/Gln $+\mathrm{G} \ln / \mathrm{Gln}$ & 51 & 49 & $1.30(0.72-2.37)$ & 0.45 \\
\hline \multirow[t]{4}{*}{ Leukopenia } & Lys/Lys & 51 & 29 & 1.0 (Ref.) & - \\
\hline & Lys/Gln & 45 & 30 & $1.17(0.61-2.28)$ & 0.74 \\
\hline & $\mathrm{Gln} / \mathrm{G} \ln$ & 19 & 6 & $0.56(0.20-1.46)$ & 0.34 \\
\hline & Lys/Gln+Gln/Gln & 64 & 36 & $0.98(0.53-1.79)$ & 0.99 \\
\hline \multirow[t]{4}{*}{ Thrombocytopenia } & Lys/Lys & 66 & 14 & 1.0 (Ref.) & - \\
\hline & Lys/Gln & 60 & 15 & $1.18(0.54-2.61)$ & 0.84 \\
\hline & $\mathrm{Gln} / \mathrm{Gln}$ & 21 & 4 & $0.89(0.29-2.79)$ & 0.99 \\
\hline & Lys/Gln+Gln/Gln & 81 & 19 & $1.11(0.52-2.28)$ & 0.85 \\
\hline \multirow[t]{4}{*}{ GI toxicity } & Lys/Lys & 64 & 16 & 1.0 (Ref.) & - \\
\hline & Lys/Gln & 58 & 17 & $1.17(0.53-2.61)$ & 0.70 \\
\hline & $\mathrm{Gln} / \mathrm{Gln}$ & 19 & 6 & $1.26(0.42-3.72)$ & 0.78 \\
\hline & Lys/Gln+Gln/Gln & 77 & 23 & $1.20(0.58-2.44)$ & 0.72 \\
\hline
\end{tabular}

Odds ratios (OR) and $95 \%$ confidence interval $(95 \% \mathrm{CI}) ;{ }^{*} \mathrm{p}<0.05$ considered as level of significance.

The role of XPD gene polymorphisms both individually and combined on the platinum-based chemotherapyinduced toxicities according to toxicity grades was shown in Table 2. In the present study, no statistical significant association was obtained for variant genotypes of XPD with platinum-based chemotherapy induced toxicities like

Table 3. TP53 (Codon 72) Genotypes Effect on Platinum-Based Chemotherapy-Induced Toxicities According to Toxicity Grades

\begin{tabular}{|c|c|c|c|c|c|}
\hline Toxicities & Genotypes & Grade $1-2$ & Grade 3-4 & OR $(95 \% \mathrm{CI})$ & $\mathrm{p}$ value \\
\hline \multirow[t]{4}{*}{ Anemia } & Arg/Arg & 28 & 38 & 1.0 (Ref.) & - \\
\hline & Arg/Pro & 54 & 47 & $0.64(0.34-1.17)$ & 0.21 \\
\hline & Pro/Pro & 8 & 5 & $0.46(0.15-1.42)$ & 0.23 \\
\hline & Arg/Pro+Pro/Pro & 62 & 52 & $0.62(0.34-1.15)$ & 0.16 \\
\hline \multirow[t]{4}{*}{ Neutropenia } & Arg/Arg & 32 & 34 & 1.0 (Ref.) & - \\
\hline & Arg/Pro & 57 & 44 & $0.73(0.39-1.33)$ & 0.34 \\
\hline & Pro/Pro & 8 & 5 & $0.59(0.19-1.80)$ & 0.55 \\
\hline & Arg/Pro+Pro/Pro & 65 & 49 & $0.71(0.39-1.33)$ & 0.28 \\
\hline \multirow[t]{4}{*}{ Leukopenia } & Arg/Arg & 39 & 27 & 1.0 (Ref.) & - \\
\hline & Arg/Pro & 66 & 35 & $0.77(0.41-1.46)$ & 0.42 \\
\hline & Pro/Pro & 10 & 3 & $0.43(0.12-1.58)$ & 0.35 \\
\hline & Arg/Pro+Pro/Pro & 76 & 38 & $0.72(0.39-1.35)$ & 0.34 \\
\hline \multirow[t]{4}{*}{ Thrombocytopenia } & Arg/Arg & 55 & 11 & 1.0 (Ref.) & - \\
\hline & Arg/Pro & 80 & 21 & $1.31(0.59-2.82)$ & 0.55 \\
\hline & Pro/Pro & 12 & 1 & $0.42(0.04-3.11)$ & 0.68 \\
\hline & Arg/Pro+Pro/Pro & 92 & 22 & $1.20(0.55-2.58)$ & 0.69 \\
\hline \multirow[t]{4}{*}{ GI toxicity } & $\operatorname{Arg} / \operatorname{Arg}$ & 53 & 13 & 1.0 (Ref.) & - \\
\hline & Arg/Pro & 78 & 23 & $1.20(0.58-2.54)$ & 0.7 \\
\hline & Pro/Pro & 10 & 3 & $1.22(0.32-4.68)$ & 0.72 \\
\hline & Arg/Pro+Pro/Pro & 88 & 26 & $1.21(0.57-2.48)$ & 0.71 \\
\hline
\end{tabular}

Odds ratios (OR) and $95 \%$ confidence interval $(95 \% \mathrm{CI}) ;{ }^{*} \mathrm{p}<0.05$ considered as level of significance. 
anemia $(\mathrm{OR}=1.40,95 \% \mathrm{CI}=0.75-2.64, \mathrm{p}>0.05 ; \mathrm{OR}=1.07$, $95 \% \mathrm{CI}=0.45-2.52, \mathrm{p}>0.05$ and $\mathrm{OR}=1.31,95 \% \mathrm{CI}=0.73$ $2.38, \mathrm{p}>0.05)$; neutropenia $(\mathrm{OR}=1.32,95 \% \mathrm{CI}=0.71$ $2.49, \mathrm{p}>0.05 ; \mathrm{OR}=1.25,95 \% \mathrm{CI}=0.52-2.94, \mathrm{p}>0.05$ and $\mathrm{OR}=1.30,95 \% \mathrm{CI}=0.72-2.37, \mathrm{p}>0.05)$; leukopenia $(\mathrm{OR}=1.17,95 \% \mathrm{CI}=0.61-2.28, \mathrm{p}>0.05 ; \mathrm{OR}=0.56,95 \%$ $\mathrm{CI}=0.20-1.46, \mathrm{p}>0.05$ and $\mathrm{OR}=0.98,95 \% \mathrm{CI}=0.53-1.79$, $\mathrm{p}>0.05)$; thrombocytopenia $(\mathrm{OR}=1.18,95 \% \mathrm{CI}=0.54-$ $2.61, \mathrm{p}>0.05 ; \mathrm{OR}=0.89,95 \% \mathrm{CI}=0.29-2.79, \mathrm{p}>0.05$ and $\mathrm{OR}=1.11,95 \% \mathrm{CI}=0.52-2.28, \mathrm{p}>0.05)$ and gastrointestinal toxicity $(\mathrm{OR}=1.17,95 \% \mathrm{CI}=0.53-2.61, \mathrm{p}>0.05 ; \mathrm{OR}=1.26$, $95 \% \mathrm{CI}=0.42-3.72, \mathrm{p}>0.05$ and $\mathrm{OR}=1.20,95 \% \mathrm{CI}=0.58$ $2.44, \mathrm{p}>0.05$ ) in lung cancer patients.

TP53 Arg72Pro genotype analysis and effects on platinumbased chemotherapy-induced toxicities

In the studied lung cancer patients, the frequency of arginine homozygous (Arg/Arg) was 36.67\% (66 patients), proline homozygous (Pro/Pro) was 7.22 \% (13 patients), arginine/proline heterozygous (Arg/Pro) was 56.11\% (101 patients), whereas combined mutant variant (Arg/Pro+Pro/ Pro) was $63.33 \%$ (114 patients).

Likewise, XPD genotypes, no significant association of Arg/Pro, Pro/Pro, and Arg/Pro+Pro/Pro genotypes of TP53 with platinum-based chemotherapy-induced toxicities were found when Arg/Arg genotype was considered as the reference group (Table 3)

\section{Discussion}

According to patients' genetic characteristics, a pharmacogenetic approach to individualize the chemotherapy regimens represents an innovative and intriguing challenge as it could deliver the most active agent to each patient. To date, platinum-based chemotherapy keeps on being the mainstay for the treatment of advanced lung cancer. However, since the cytotoxic impacts of platinum are not explicit, multiple systems appear to be involved in the mechanism of toxicity during chemotherapy. Therefore, researchers had an enormous interest in identifying the effect of genetic factors on platinum-based chemotherapy-induced toxicities taking into account interindividual differences. Hence, the detection of SNPs that assists in predicting either sensitivity or toxicity to chemotherapy is of great value in choosing patients who will be improved from a chemotherapy regimen. In the current study, we included 180 lung cancer patients treated with platinum-based regimens and explored the effect of XPD Lys751Gln and TP53 Arg72Pro genetic polymorphisms on platinuminduced grade 1-2 and 3-4 toxicities.

In most studies, the identification of genetic polymorphisms that influence platinum-related toxicities was indecisive. Polymorphisms in genes that encode nucleotide excision repair (NER) pathway are significantly the most critical genetic determinants with susceptibility to platinum-based chemotherapy-induced toxicities (Perez-Ramirez et al., 2017). The NER pathway repairs DNA intrastrand crosslink's caused by platinum-based chemotherapy, and XPD is among the most common candidate genes related to platinum-based toxicities
(Zhang et al., 2018). However, no significant association between the genotypes in XPD codon 751 and platinuminduced severe toxicities was observed in our analysis. Although several studies have addressed the correlation between SNPs in codon 751 of XPD and platinum-based chemotherapy response in NSCLC patients, only a few studies have focused on chemotherapy toxicity (Giachino et al., 2007; Tibaldi et al., 2008; Booton et al., 2006). Nevertheless, one study anticipated that the grade of neutropenia manifested a significant association with the XPD haplotype, where the XPD751 lysine allele was related to greater Grade 4 neutropenia in contrast to the XPD751 glutamine allele. However, no significant relation was found between XPD haplotype and anemia, thrombocytopenia, and/or nonhematologic toxicity (Booton et al., 2006).

Moreover, no significant trend was observed in our study toward the association between TP53 gene polymorphisms and the risk of platinum-based chemotherapy-induced toxicities with anemia, neutropenia, leukopenia, thrombocytopenia, and gastrointestinal toxicity in lung cancer patients similar to XPD genotypes. These findings align with a previous meta-analysis conducted with four studies consisting of 1,033 patients to identify the correlation between TP53 Arg72Pro polymorphism and grade 3-4 hematological toxicity. However, no significant association of Arg72Pro polymorphism with grade 3-4 hematological toxicity was found $(\mathrm{OR}=0.82$, 95\% CI: $0.59-1.15, \mathrm{p}=0.25$ ) (Liu et al., 2020). In this study, the lack of such association can be ascribed to the small sample size, resulting in a low power to identify significant differences in the distribution of genotypes between grade 1-2 and grade 3-4. Moreover, though all patients of this study were treated with platinum-based agents, the use of non-platinum drugs, such as paclitaxel, gemcitabine, etoposide, docetaxel, and doxorubicin, may influence toxicity profiles as a part of the chemotherapy regimens. In addition, the cumulative dosage aggravates platinum-induced toxicities; hence, several cycles of chemotherapy can also affect the results. Furthermore, other factors may affect platinum-induced toxicities, such as tumor molecular features, demographic characteristics, comorbidity, and intestinal bacteria.

In conclusion, the results of our study suggested no significant association of XPD Lys751Gln and TP53 Arg72Pro polymorphisms with the platinum-based chemotherapy-related toxicities in Bangladeshi lung cancer patients. Therefore, further prospective, highquality pharmacogenomics research with a large sample size is required to evaluate the proper role of genetic polymorphisms on platinum-related toxicities in lung cancer patients. Eventually, by conducting additional studies in this field, we might be able to foster a much more precise comprehension of genetic variations among individuals and their association in determining treatment outcomes along with treatment-related toxicities. As a result, in the future, it may be possible to select chemotherapies and treatments according to individual genetic profiles, considering their probability of having treatment-related severe toxicities. 


\section{Author Contribution Statement}

Tahsin Nairuz conceptualized, designed, performed experiments, data analysis and interpretation and drafted the manuscript. Most Umme Bushra follows up patients' enrollment, helps in sample collection and data management. Yearul Kabir provided overall concept, guidance and support to the study and critically reviewed the manuscript. All authors have read and approved the final manuscript.

\section{Acknowledgements}

Authors thank all physicians, nurses and other personnel of Ahsania Mission Cancer and General Hospital, Dhaka Medical College Hospital, and Bangabandhu Sheikh Mujib Medical University, Dhaka, Bangladesh for providing support in collecting blood of the study subjects and patient counseling. We also thank all the study subjects for participating in this study. The authors are thankful to Mr. Mostafijur Rahman of Department of Biochemistry and Molecular Biology, and Dr. Noor Ahmed Nahid, Department of Clinical Pharmacy and Pharmacology, University of Dhaka, for technical help and collection the patients' samples. The authors are also thankful to all the members of the Institutional Ethical Review Committees of the Department of Biochemistry and Molecular Biology, University of Dhaka, Bangladesh for approval of the study protocol. This research received no specific grant from any funding agency in the public, commercial, or not-for-profit sectors. None of the authors had a personal or financial conflict of interest.

\section{References}

Bailes SM, Devers JJ, Kirby JD, Rhoads DD (2007). An inexpensive, simple protocol for DNA isolation from blood for high-throughput genotyping by polymerase chain reaction or restriction endonuclease digestion. Poult Sci, 86, 102-6.

Benhamou S, Sarasin A (2002). ERCC2/XPD gene polymorphisms and cancer risk. Mutagenesis, 17, 463-9.

Bojesen SE,Nordestgaard BG (2008). The common germline Arg72Pro polymorphism of $\mathrm{p} 53$ and increased longevity in humans. Cell Cycle, 7, 158-63.

Booton R, Ward T, Heighway J, et al.(2006) Xerodermapigmentosum group D haplotype predicts for response, survival, and toxicity after platinum-based chemotherapy in advanced nonsmall cell lung cancer. Cancer, 106, 2421-7.

Clarke H, Pallister CJ (2005). The impact of anaemia on outcome in cancer. Clin Lab Haematol, 27, 1-3.

Common Terminology Criteria for Adverse Events (CTCAE) v5.0 Publish Date: November 27, 2017.

D'Addario G, Pintilie M, Leighl NB, et al (2005). Platinumbased versus non-platinum-based chemotherapy in advanced non-small-cell lung cancer: a meta-analysis of the published literature. J ClinOncol, 23, 2926-36.

FerlayJ (2010). GLOBOCAN 2008 v1. 2, Cancer incidence and mortality world-wide: IARC Cancer Base No. 10. http:// globocan.iarc.

Ferlay J, Shin HR, Bray F, et al (2010). Estimates of worldwide burden of cancer in 2008: GLOBOCAN 2008. Int J Cancer, 127, 2893-917.
Giachino DF, Ghio P, Regazzoni S, et al.(2007). Prospective assessment of XPD Lys751Gln and XRCC1 Arg399Gln single nucleotide polymorphisms in lung cancer. Clin Cancer Res, 13, 2876-81.

Giovannetti E, Pacetti P, Reni M, et al (2011). Association between DNA-repair polymorphisms and survival in pancreatic cancer patients treated with combination chemotherapy. Pharmacogenomics, 12, 1641-52.

Glezerman IG, Jaimes EA. (2016). Chemotherapy and kidney injury. Am Soc Nephrol, 2016, 1-10.

Hildebrandt MA, Gu J, Wu X (2009). Pharmacogenomics of platinum-based chemotherapy in NSCLC. Expert Opin Drug MetabToxicol, 5, 745-55.

Hussain SA, Sullivan R (2013). Cancer control in Bangladesh. Jpn J Clin Oncol, 43, 1159-69.

Jung Y, Lippard SJ (2007). Direct cellular responses to platinuminduced DNA damage. Chem Rev, 107, 1387-407.

Liu W, Wang Y, Luo J, Yuan H, Luo Z (2020). Genetic polymorphisms and platinum-based chemotherapy-induced toxicities in patients with lung cancer: a systematic review and meta-analysis. Front Oncol, 9, 1573.

Mitra AK, Singh N, Garg VK, et al (2009). Statistically significant association of the single nucleotide polymorphism (SNP) rs13181 (ERCC2) with predisposition to squamous cell carcinomas of the head and neck (SCCHN) and breast cancer in the north Indian population. J Exp.Clin Cancer Res, 28, 104.

NSCLC Meta-Analyses Collaborative Group, NM.-AC (2008). Chemotherapy in addition to supportive care improves survival in advanced non-small-cell lung cancer: a systematic review and meta-analysis of individual patient data from 16 randomized controlled trials. J Clin Oncol, 26, 4617.

Papadakis ED, Soulitzis N, Spandidos DA (2002). Association of 53 codon 72 polymorphism with advanced lung cancer: the Arg allele is preferentially retained in tumours arising in Arg/Pro germline heterozygotes. Br J Cancer, 87, 1013-8.

Pérez-Ramírez C, Cañadas-Garre M, Molina MÁ, et al.(2017). Contribution of genetic factors to platinum-based chemotherapy sensitivity and prognosis of non-small cell lung cancer. Mutat Res Rev Mutat Res, 771, 32-58.

Pivot X, Guardiola E, Etienne M, et al (2000). An analysis of potential factors allowing an individual prediction of cisplatin-induced anaemia. Eur J Cancer, 36, 852-7.

Pujol JL, Barlesi F, Daurès JP (2006). Should chemotherapy combinations for advanced non-small cell lung cancer be platinum-based? A meta-analysis of phase III randomized trials. Lung Cancer, 51, 335-45.

Sung H, Ferlay J, Siegel RL, et al (2021). Global cancer statistics 2020: GLOBOCAN estimates of incidence and mortality worldwide for 36 cancers in 185 countries. CA Cancer J Clin, 71, 209-49.

Tibaldi C, Giovannetti E, Vasile E, et al (2008). Correlation of CDA, ERCC1, and XPD polymorphisms with response and survival in gemcitabine/cisplatin-treated advanced non-small cell lung cancer patients. Clin Cancer Res, 14, 1797-803.

Travis WD (2011). Pathology of lung cancer. Clin Chest Med, 32, 669-92.

USDHHS: US Department of Health and Human Services(2009). Common terminology criteria for adverse events (CTCAE) version 4.0. National Institutes of Health, National Cancer Institute, 4(03).

WHO: World Health Organization (2017). World Health Rankings. Bangladesh: Lung Cancers. [Availablefrom:https:// www.worldlifeexpectancy.com/bangladesh-lungcancers;Lastaccessed: March 28, 2020]. 
WMA: World Medical Association (2013). World Medical Association Declaration of Helsinki Ethical Principles for Medical Research Involving Human Subjects. JAMA, 310, 2191-4.

Zhang R, Zhou F, Cheng L, et al (2018). Genetic variants in nucleotide excision repair pathway predict survival of esophageal squamous cell cancer patients receiving platinum-based chemotherapy. Mol Carcinog, 57, 1553-65.

\section{(ब) $\odot$}

This work is licensed under a Creative Commons AttributionNon Commercial 4.0 International License. 